\title{
FLAKE FRACTURE OF THE TALUS PROGRESSING TO OSTEOGHONDRITIS DISSECANS
}

\author{
Kexieth L. Marks, Ipswich, ExGLaNd
}

Flake fractures of the talus are uncommon injuries, usually associated with marked inversion or eversion of the foot and ankle, coupled with tearing of the medial internal lateral ${ }_{j}$ or the lateral [fibular collateral] ligament or of both ligaments. Watson-Jones (1943), relating ninety-seren cases of fracture and fracture-dislocation of the talus and navicular bone in the Royal Air Force in two years of war, noted only eight avulsion or flake fractures of the medial or lateral border of the talus. I should like to add one case, which has progressed to osteochondritis dissecans.

\section{CASE REPORT}

A man aged thirty-nine years, stepping out of a brake, underestimated the distance to the ground so that his weight fell on to the outer border of his left foot, turning it inwards beneath him. He felt an immediate acute pain in the outer side of his ankle, but was able to walk from the spot with pain and a limp.

On examination, there were marked swelling beneath the lateral malleolus and tenderness over the whole insertion of the lateral ligament, most marked over the attachment of the anterior and middle fasciculi to the talus and calcaneum respectively. There was no tenderness over the shaft of the tibia, nor over the medial malleolus. Flexion and extension at the ankle were normal, but there was limitation of active inversion by pain and of eversion by swelling. By comparison with the opposite foot and ankle passive inversion was increased.

Radiographic examination-A lateral view did not show any bony lesion. In the anteroposterior view there was evidence of an old inversion

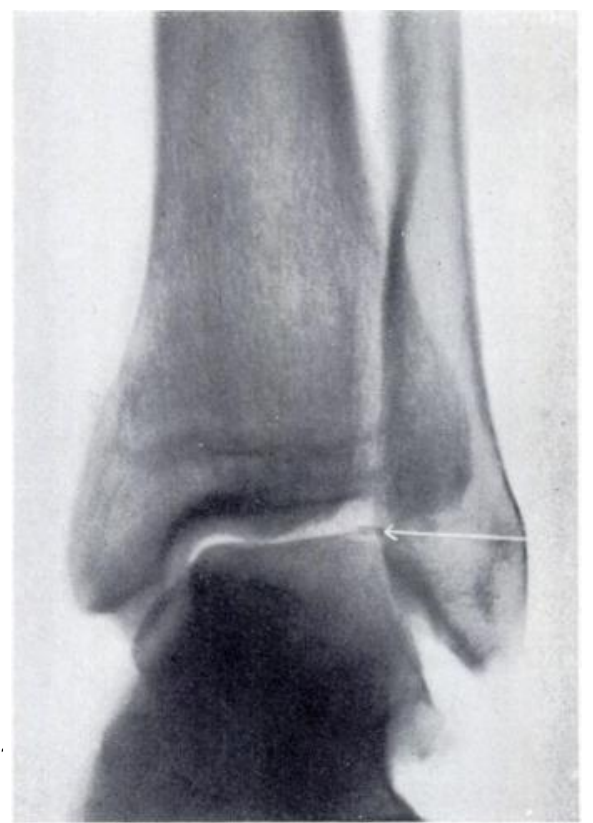

FIG. 1

Radiograph taken soon after the injury, showing flake fracture of the talus. injury with a bony fragment beneath the tip of the fibula, and a recent flake fracture of the superolateral border of the talus (Fig. 1). There was also a well marked soft tissue swelling over the lateral malleolus.

Treatment-The ankle was immobilised in a short non-weight-bearing plaster for three weeks, and a below-knee walking plaster for a further three weeks.

Progress-Eight months after the injury, the patient walked without limp or pain, though there was some thickening of the joint and slight tenderness on palpation immediately in front of the lateral malleolus. Further radiographic examination showed abnormal bone formation on the medial aspect of the medial malleolus, doubtless caused by arulsion of the medial ligament from the malleolus at the time of the injury. The flake fracture of the talus had not united, and with the consequent underlying excavation the lesion now resembled osteochondritis dissecans (Figs. 2 and 3). 
At this juncture the patient was not anxious for any further treatment. But three months later (eleven months after the injury) he began to complain of pain in the ankle after walking more than one or two miles. Further examination revealed thickening around

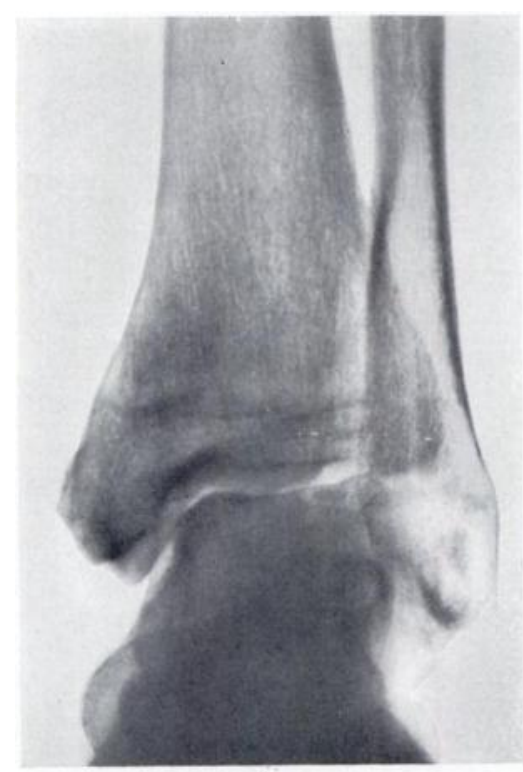

FiG. 2

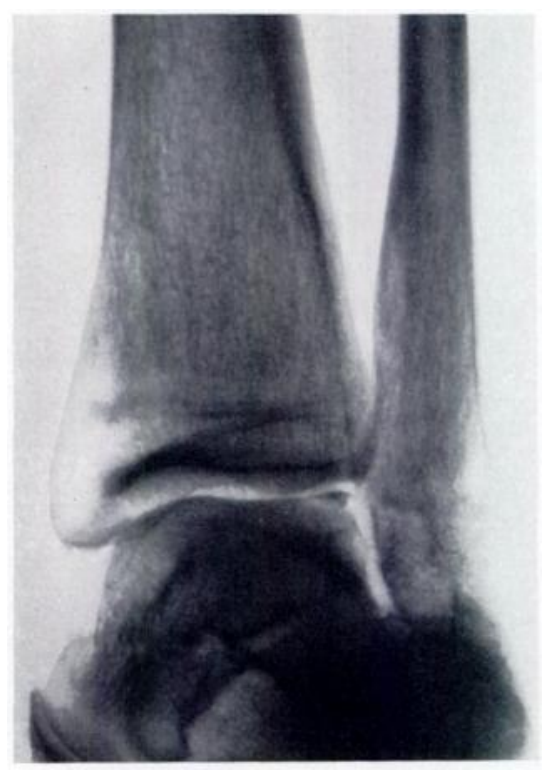

FIg. 3

Eight months after injurv. Antero-posterior (Fig. 2) and oblique (Fig. 3) views showing osteochondritis dissecans.

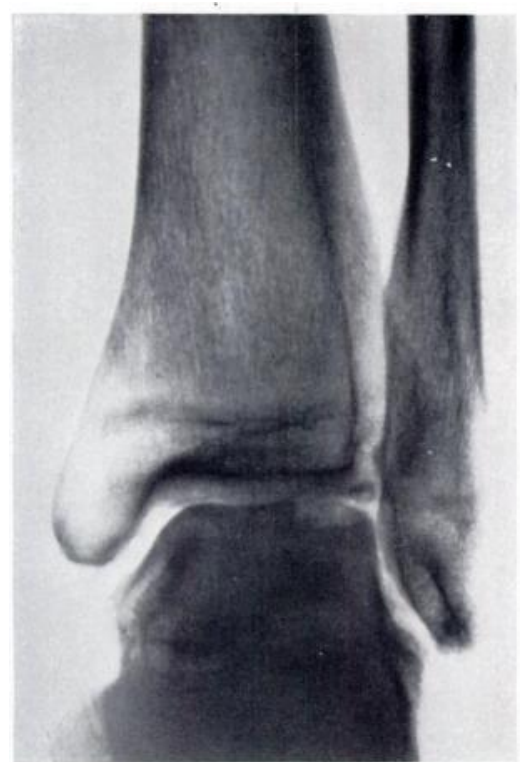

Fig. 4

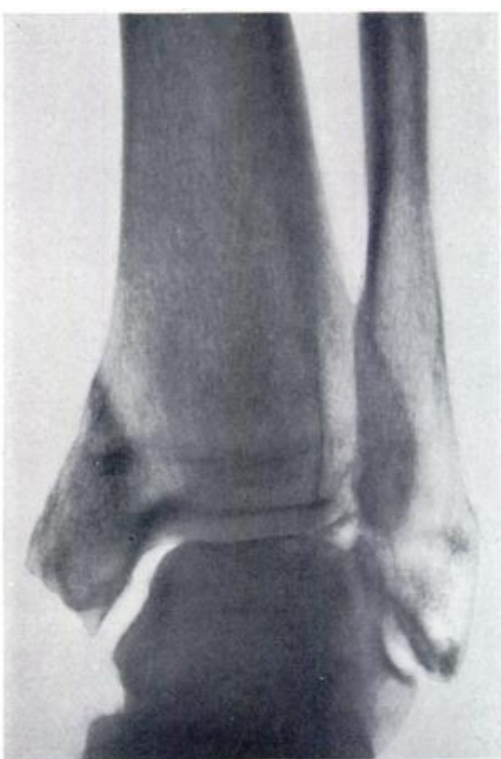

Fig. 5

Two years after injury. The antero-posterior view (Fig. 4) shows osteochondritis dissecans of the supero-lateral margin of the talus. The oblique view (Fig. 5) suggests that the bone fragment is becoming loose and is beginning to separate.

the joint, and pain on extremes of movement in all directions. Radiographs showed developing osteoarthritis; the lesion of osteochondritis dissecans was still visible, and the fragment appeared to be separating from the talus.

VOL. 34 B, NO. 1, FEBRUARY 1952 
In a further review carried out thirteen months later (two years after the injury) no further clinical deterioration was observed. Radiographs showed osteochondritis dissecans of the supero-lateral angle of the talus, and a small detached bony body in the lateral compartment of the ankle joint. Chronic ostoearthritic changes were present, and the ligamentous injuries already noted were still evident (Figs. 4 and 5). Further treatment is now under consideration.

\section{DISGUSSION}

After a moderately severe adduction-inversion injury, the patient suffered a flake fracture of the supero-lateral angle of the talus. Presumably the fragment was buckled off the lateral border of the talus by the contiguous articular surface of the lateral malleolus.

The significant feature of this case is the progression of what was originally a simple flake fracture to a definite osteochondritis dissecans. This direct relationship between injury and the onset of the lesion has already been noted by Vaughan and Stapleton (1947).

The site of separation in this patient was not the most common for osteochondritis dissecans of the talus. Ray and Coughlin (1947) reported fourteen examples of osteochondritis dissecans of the talus, eleven on the supero-medial border, and only three on the supero-lateral. In none of their cases did they record radiographic evidence of a flake fracture of the talus, nor has a study of the literature revealed a similar case.

\section{SUMMARY}

1. A case of flake fracture of the talus progressing to osteochondritis dissecans is reported.

2. The relationship between direct injury and the onset of the lesion is noted.

3. The sequence of events was observed radiographically and clinically for two years from the date of the original injury.

My thanks are due to the Director-General of Medical Services of the Ministry of Pensions for permission to publish this case.

\section{REFERENCES}

Ray, R. B., and Coughlin, E. J., Jr. (1947): Osteochondritis Dissecans of the Talus. Journal of Bone and Joint Surgery, 29, 697.

Vaughan, C. E., and Stapleton, J. G. (1947): Osteochondritis Dissecans of the Ankle. Radiology, $49,72$. Warson-Jones, R. (1943): Fractures and Joint Injuries. Third edition. Vol. II, p. 825. Edinturgh: E. \& S. Livingstone Ltd. 